\title{
A Study on Chinese Labor Cost Stickiness
}

\author{
Xiaofeng Tian \\ College of Management \\ Wuhan University of Science and Technology \\ Hubei, China
}

\author{
Mi Xiong \\ College of Management \\ Wuhan University of Science and Technology \\ Hubei, China \\ 1203474180@qq.com
}

\begin{abstract}
By using the data of Chinese listed companies from 2008 to 2015,the labor cost stickiness of China is explored in this paper. By the study, it is found that there exists the labor cost stickiness in Chinese listed companies, and the degrees of labor cost stickiness have differences in the enterprises with different equity natures, and the labor cost stickiness of state-owned enterprises is significantly stronger than that of private enterprises. After the further introduction of capital intensity, it is found that the higher the degree of capital intensity is, the stronger the labor cost stickiness of enterprises is, and this phenomenon is more obvious in the state-owned enterprises.
\end{abstract}

Keywords_labor cost stickiness; equity nature; capital intensity

\section{INTRODUCTION}

Since 2002, the "labor shortage" has started to appear in "Pearl River Delta" of China, and it has been in the trend that the scope is expanding continually. After 2005, the "labor shortage" began to spread from the eastern region to the central and eastern region. The shortage of workers is mainly the young labor force at the age from 18 to 25 years old, and it is mainly concentrated in the manufacturing and catering services, which account for about $80 \%$ of the total gap. In terms of the labor costs of enterprises in China, the enterprises are more difficult than before in adjusting labor costs because of the population supply structural imbalance, the increase in wages and the increase in labor protection.

The cost stickiness refers to the asymmetry of revenue and cost changes. The percentage of cost increase caused by revenue increase is greater than the percentage of cost reduction caused by the reduction in the equal revenue amount. The labor cost is the labor cost of an enterprise, which is also a kind of enterprises' costs. The labor cost stickiness is the percentage of labor cost increase caused by the revenue increase is greater than the percentage of labor cost reduction caused by the reduction in equal revenue amount, and the greater the asymmetry is, the stronger the stickiness is. Labor costs can be broken down into the most basic "quantity" (labor quantity used) and "price" (per capital salary). When an enterprise's revenue increases, the quantity of employees or per capital salary will increase, and thereby the labor cost will increase. When an enterprise's revenue reduces, it will reduce the quantity of employees or per capital salary so as to reduce the costs. But this adjustment is often affected by internal and external factors, such as managers' expectations of the enterprise development, the adjustment costs of enterprises, government intervention and so on, which lead to the asymmetry of labor cost change when an enterprise's revenue changes. The labor cost stickiness arises. If an enterprise's cost stickiness is too strong, it will easily lead to the slow response efficiency when the enterprise faces business changes, and the slow response efficiency will directly result in the reduction of the enterprise's earnings.

In this paper, we first use the research method of reviewing and combing the cost stickiness through the literature. Based on that, we combine the characteristics of labor costs, analyze whether its stickiness exists and the main influencing factors from the theory, and then put forward the research assumptions. Second, we choose the appropriate research models, and explain the variables, use stata software to make empirical checks, and put forward reasonable policies and recommendations through the empirical results. It is hoped that this study can provide the data support for the existence of labor cost stickiness of listed companies in China, reveal the differences of labor cost stickiness between the enterprises with different equity natures and the enterprises with different capital densities. So as to make the relevant enterprises to pay attention to the labor cost stickiness, and thus improve the level of labor cost management.

\section{TheOretical ANALysis AND RESEARCH Assumptions}

Foreign scholars started to study the cost stickiness earlier. They mostly discussed the existence, natures and causes of cost stickiness in the early stage of studying the cost stickiness. Using the annual financial data of 7629 listed companies in America from 1979 to 1998, Anderson et al. (2003) [1] conducted empirical studies on "sales expenses, general expenses and administrative expenses" (SG\&A) of American listed companies, and they found that every time the sales revenue increased by $1 \%$, and the cost would increase by $0.55 \%$.However every time the sales revenue reduced by $1 \%$, and the cost would reduce by $0.35 \%$. This verified that "sales expenses, general expenses and administrative expenses" (SG \& A) of American listed companies had the asymmetry in the directions of changes. It verified the existence of cost stickiness. Using the financial data of 2441 listed companies in America that met the constrained conditions of their models from 1992 to 2006, Alexander Brüggen · Jens Oliver Zehnder(2014) analyzed whether the cost stickiness existed based on the basic model of the cost stickiness of Anderson et al. (2003). They reached a conclusion that every time the sales revenue increased by $1 \%$, and the cost would increase by $0.76 \%$. Every time the sales revenue reduced by $1 \%$, and the cost would reduce by $0.46 \%$. This also verified the existence of cost stickiness. Sun Zheng and Liu Hao (2004)[2] through studying 
the financial data of 292 listed companies in China from 1994 to 2001.They first proposed that the sales management costs of listed companies in China had the stickiness, and they thought that the cost stickiness of Chinese listed companies may be caused by the self-interest behavior of management levels. By selecting the annual financial data of 824 listed companies in China from 2009 to 2012 as samples, and according to the divisions of listed companies' industries by China Securities Regulatory Commission (CSRC), and Wang man et al. (2014) studied and made a conclusion that the total cost stickiness of Chinese listed companies existed commonly. However, there were differences in the degrees of the cost stickiness between the industries. The operating cost stickiness of real estate industry is prominent, and the cost stickiness of management costs and financial costs in manufacturing industry is the most prominent. The aforesaid studies show the existence of cost stickiness. According to previous studies, it is showed that the cost stickiness of enterprises mainly comes from three aspects: adjustment costs, managers' optimistic expectations and opportunistic behaviors (Banker et al., 2011)[3].

Compared to other cost stickiness, the studies of labor cost stickiness are not a lot. Cai Fang (2010) studied and found that China was in the inflection point of Lewis, a stage when the demographic dividends gradually disappeared. Cai Fang (2013) [4] made the years when the proportion of the working age population in the proportion of the total population reversed as the years when the demographic dividends disappeared. According to the data from Statistical Yearbook of China, it is shown that the proportion of Chinese working age population in 2010 to the total population had inversion. The labor markets have gradually responded to that, on the one hand, it showed in that the nationwide "migrant worker shortage" phenomena arose constantly. On the other hand, it showed in that migrant workers' wages increased year by year. "Shortage of migrant workers" and wages increasing year by year caused by demographic structure transitions made the companies adjust labor costs, and the cost stickiness was increased because the adjustment cost was too much. Liu Yuanyuan and Liu Bin (2014)[5] studied the impact of labor protection on labor costs from the implementation of The Labor Contract Law. They studied and found the labor protection exacerbated the labor cost stickiness of enterprises, and it also exacerbated the possibility that the enterprises replaced manual work with machines. The shortage of labor force amount, the increase in workers' wages and the labor protection all may lead to the occurrence of labor cost stickiness, and therefore we put forward the following assumptions:

Assumption 1: The labor cost stickiness exists in Chinese listed companies.

China is a country with a large population, and the employment problem has been very prominent. Thus, solving the employment problems in the regions have become important tasks for all levels of governments and officials, and also have become one of their main assessment indicators (Zhang Min et al., 2013)[6]. Management levels of state-owned enterprises are similar to "politicians", whose behaviors are more driven by political motives. The governments (especially the local governments) will restrict the layoffs of enterprises (especially state-owned enterprises) through all kinds of means, that the local governments solve the pressure of employment becomes one of the important factors that a large quantity of redundant personnel exist in state-owned listed companies (Zeng Qingsheng and Chen Xinyuan, 2006; Xue Yungui and Bai Yunxia, 2008). State-owned enterprises have more policy intervention in hiring employees compared to private enterprises, and the general rise in wages caused by the population structure transforms makes state-owned enterprises have greater adjustment costs in the control of staff costs. Compared with state-owned enterprises, although private enterprises are better than state-owned enterprises in the flexibility of hiring employees. They accept more labor force, so the population structure transforms may have an impact on their adjustment costs.

Assumption H2a: The labor cost stickiness of state-owned enterprises is greater.

Assumption H2b: The labor cost stickiness of private enterprises is greater.

Capital-intensive industries refer to the industries and departments that require more capital investment. For the capital-intensive industries in the unit cost of goods, capital costs have the larger proportion compared to labor costs in the unit product costs, and the amount of fixed capital and circulating capital occupied by each worker is higher, such as metallurgical industry, fossil oil industry, machinery manufacturing and other heavy industries. Most of these industries are state-owned enterprises whose talent needs are mostly technical jobs, and the structural imbalance of labor force in China makes technical workers and high-end talents in short supply. Thus, this part of the population is short in the "quantity", and is relatively high in the "price". When the capital-intensive enterprises' revenue increase, the increase in the amount of business make enterprises may increase the number of employees. But this part of the talents belongs to the scarce resources and needs a higher cost to get. And when the revenue reduces, the enterprises' managers may expect that the future situation will be better and do not want to cut down the number of employees. Therefore, the following assumptions are made:

Assumption H3a: The labor cost stickiness of capitalintensive state-owned enterprises is greater.

\section{Model Design, VARIABle Definition And SAMPle SELECTION}

In this paper, we will verify the three types of assumptions proposed above by learning from the means of Anderson et al. (2003).

First, we verify the existence of labor cost stickiness, and put forward the following Model 1:

LnLabcost $_{i t}=\beta_{0}+\beta_{1}$ LnIncome $_{i t}+\beta_{2}$ Dec $_{i t} \times$ LnIncome $_{i t}+\varepsilon_{i t}$

Of it, LnLabcost ${ }_{i t}$ indicates the natural logarithms after the labor cost in the " $\mathrm{t}$ " year is divided by the labor cost in the " $\mathrm{t}$ 1 "year of the "i” company. LnIncome ${ }_{i t}$ indicates the natural logarithms after the business revenue in the " $\mathrm{t}$ " year is divided by the business revenue in the " $\mathrm{t}-1$ " year of the "i" company. Dec $_{\text {it }}$ is the dummy variable whether the business revenue of 
the "i" company decreases from the "t-1" year to the " $\mathrm{t}$ " year. In this model, when the revenue increases by $1 \%$, and the cost will change $\beta_{1} \%$. When the revenue decreases, and the cost will change $\left(\beta_{1}+\beta_{2}\right) \%$. Previous studies have shown that if $\beta_{2}$ is negative, and it will show the cost stickiness exists.

For the verification of Assumption $\mathrm{H} 2 \mathrm{a}$ and $\mathrm{H} 2 \mathrm{~b}$, we also use Model 1, make the full samples divided into a state-owned enterprise group and a private enterprise group, and compare the values of $\beta_{2}$ obtained from the regressions. It is shown that the smaller the values of $\beta_{2}$ are, the stronger the labor cost stickiness is.

For the verification of Assumption H3a, the following Model 2 is proposed:

$$
\begin{aligned}
& \text { LnLabcost }_{i t}=\beta_{0}+\beta_{1} \text { LnIncome }_{i t}+\beta_{2} \text { Dec }_{i t} \times \text { LnIncome }_{i t}+ \\
& \beta_{3} \text { AssetItensity }_{i t} \times \text { Dec }_{i t} \times \text { LnIncome }_{i t}+\beta_{4} \text { Lsp }_{i t} \times \text { Dec }_{i t} \\
& \times \text { LnIncome }_{i t}+\varepsilon_{i t}
\end{aligned}
$$

On the basis of Model 1, AssetItensity (capital intensity) variable and $\mathrm{Lsp}_{\mathrm{it}}$ (the largest shareholder's shareholding ratio) control variable are added to Model 2. In this model, if $\beta_{3}$ is significantly negative and the capital intensity will intensify the enterprises' labor cost stickiness. Respectively, we make the state-owned enterprise group and the private enterprise group conducted the regressions by using Model 2. if $\beta_{3}$ obtained from the regressions both are significant and negative, and the values of $\beta_{3}$ can be compared. If $\beta_{3}$ of the state-owned enterprise group is less than $\beta_{3}$ of the private enterprise group. Assumption H3a will be right. If only $\beta_{3}$ of the state-owned enterprise group is negative and significant, and assumption H3a will be also right.

The specific definitions of variables used in the aforesaid

\begin{tabular}{|c|c|}
\hline Variable & Definitions and calculation formulas \\
\hline Lnlabcost $_{\text {it }}$ & $\begin{array}{l}\text { The natural logarithms expressed after the labor cost in the } \\
\text { " } t \text { " year is divided by the labor cost in the "t-1" year of the } \\
\text { "i" company. The labor cost is that the year's cash paid to } \\
\text { employees and paid for employees" in the cash flow } \\
\text { statement + the year end number minus the year beginning } \\
\text { number of "the salary which should be paid to the } \\
\text { employees" in the balance sheet }\end{array}$ \\
\hline LnIncome $_{\text {it }}$ & $\begin{array}{l}\text { The natural logarithms expressed after the business revenue } \\
\text { in the " } \mathrm{t} \text { " year is divided by the business revenue in the " } \mathrm{t}-1 \text { " } \\
\text { year of the "i" company }\end{array}$ \\
\hline Dec $_{\text {it }}$ & $\begin{array}{l}\text { For the dummy variable whether the business revenue of the } \\
\text { "i" company from the "t- } 1 \text { " year to the "t" year reduces, if it } \\
\text { reduces, } 1 \text { is chosen; if not, } 0 \text { is chosen }\end{array}$ \\
\hline AssetItensity ${ }_{i t}$ & $\begin{array}{l}\text { Capital intensity. The " } \mathrm{t} \text { " year-end assets / the business } \\
\text { revenue in the " } \mathrm{t} \text { " year of the "i" company }\end{array}$ \\
\hline Lspit $_{\text {it }}$ & The ratio of the largest shareholder holdings \\
\hline
\end{tabular}
models are shown in Table 1:

TABLE I. SPECIFIC DEFINITION OF VARIABLES

In this paper, we choose the data of the A-share listed nonfinancial and non-ST type listed companies from 2008 to 2015, and screen according to the following conditions: eliminating the observed values that the data was missing from 2008 to 2015, eliminate the observed values that the total assets or sales revenue are less than zero or equal to zero, and eliminating the observed values that the natures of enterprises' equities have changes. In order to weaken the effect of abnormal values, we make the Winsorize treatments for respective $1 \%$ of all successive variables' beginning and end in this paper. As the calculation of labor costs needs the beginning number of the year, and the calculation of LnLabcost $t_{i t}$ is the specific value between the year's value and the previous year's value, we finally concluded that the observed values from 2010 to 2015 were a total of 5058, and there were 843 listed companies. The companies' equity data is taken from the CSMAR database, and the other data is all taken from the RESSET database.

\section{EMPIRICAL RESULT ANALYSIS}

\section{A. Descriptive Statistics}

In Table 2, the descriptive statistics of main variables in this paper is reported. The average value of labor cost changes is 0.1514 , and the median is 0.1286 . The average value of revenue changes is 0.1057 , and the median is 0.0964 . There is $28.76 \%$ of observed value, the year's revenue declined, which was slightly higher than $26.41 \%$ reported by Liang Shangkun (2013). In general, both the revenue and the cost have a trend of positive growth and the average growing rate of labor costs is faster than that of the revenue. Indicating that enterprises' profits are squeezed by labor costs' rising.

TABLE II. DESCRIPTIVE STATISTICS

\begin{tabular}{|c|c|c|c|c|c|c|}
\hline Variable & $\begin{array}{c}\text { Number of } \\
\text { samples }\end{array}$ & $\begin{array}{c}\text { Average } \\
\text { value }\end{array}$ & Median & $\begin{array}{c}\text { Standard } \\
\text { deviation }\end{array}$ & $\begin{array}{c}\text { Minimum } \\
\text { value }\end{array}$ & $\begin{array}{c}\text { Maximum } \\
\text { value }\end{array}$ \\
\hline Lnlabcost $_{\text {it }}$ & 5058 & 0.1514 & 0.1286 & 0.1913 & -0.3375 & 0.9419 \\
\hline LnIncome $_{\text {it }}$ & 5058 & 0.1057 & 0.0964 & 0.2575 & -0.6564 & 1.0701 \\
\hline AssetItensity $_{\text {it }}$ & 5058 & 1.6804 & 1.2228 & 1.5372 & 0.1225 & 9.3951 \\
\hline Lsp $_{\text {it }}$ & 5058 & 0.3651 & 0.3519 & 0.1544 & 0.0339 & 0.8999 \\
\hline Dec $_{\text {it }}$ & 5058 & 0.2877 & 0 & 0.4527 & 0 & 1 \\
\hline
\end{tabular}

\section{B. Results of Empirical Verification}

Using the verification of Model for the existence of labor costs, the regression results are as shown in Column (1) of Table 3 , and it can be seen that $\beta_{1}=0.4088$. When the revenue increases by $1 \%$, the labor cost will increase by $0.4088 \% ; \beta_{2}=-$ 0.1979 , When the revenue declines by $1 \%$, the labor cost will decline $\beta_{1}+\beta_{2}=0.2109 \%$. The revenue and the labor cost changes are asymmetric, and the labor cost stickiness is $0.1979 \%$, which is consistent with the assumptions that the aforesaid labor cost stickiness exists. It is consistent with the study on the labor cost stickiness of Liu Yuanyuan and Liu Bin (2014).

Using the regression results of Model 1 for Assumption $\mathrm{H} 2 \mathrm{a}$ and $\mathrm{H} 2 \mathrm{~b}$, as are shown in Table 3. In the state-owned enterprises group $\beta_{2}=-0.334$ and is significant, and in the private enterprise group $\beta_{2}=-0.068$ and is significant. The regression results show whether state-owned enterprises or private enterprises both have the labor cost stickiness, and the labor cost stickiness of state-owned enterprises is significantly stronger than that of private enterprises. So assumption $\mathrm{H} 2 \mathrm{a}$ is right. That is consistent with the status of our country. China's state-owned enterprises are supervised by the governments, and if the employment pressure is to be solved, the layoff cost is more (Zeng Qingsheng and Chen Xinyuan, 2006; Xue Yungui and Bai Yunxia, 2008). 
TABLE III. REGRESSION RESULTS OF MODEL 1

\begin{tabular}{|c|c|c|c|}
\hline Variable & Full sample & State-owned & Private \\
\hline$\beta_{0}$ & $0.098(29.16)^{* * *}$ & $0.079(19.11)^{* * *}$ & $0.126(21.25)^{* *}$ \\
\hline$\beta_{1}$ & $0.409(31.14)^{* * *}$ & $0.457(27.59) * * *$ & $0.353(15.90)^{*}$ \\
\hline$\beta_{2}$ & $-0.198(-7.78)^{* * *}$ & $-0.334(-9.40)^{* * *}$ & $-0.068(-1.83)^{* *}$ \\
\hline \multicolumn{4}{|l|}{$\beta_{3}$} \\
\hline \multicolumn{4}{|l|}{$\beta_{4}$} \\
\hline $\mathbf{R}^{2}$ & 0.410 & 0.358 & 0.490 \\
\hline F-statistic & 645.62 & 480.98 & 187.24 \\
\hline Number & 5058 & 3360 & 1698 \\
\hline
\end{tabular}

two-tailed verification at $10 \%, 5 \%$ and $1 \%$ levels. The following are the same.

Using the verification of Model 2 for Assumption H3a, the regression results are as shown in Table 4 . The capital density coefficient $\beta_{3}=-0.03$ obtained from the full samples indicates that the capital density increases the enterprises' labor cost stickiness. After the samples are divided into a state-owned enterprise group and a private enterprise group, the state-owned enterprise group $\beta_{3}=-0.036$, and it is significant at the level of $5 \%$; the private enterprise group $\beta_{3}=-0.031$, and it is significant at the level of $10 \%$. They indicate that the impact of capital intensity on state-owned enterprises is more obvious. Assumption H3a is right.

TABLE IV. REGRESSION RESULTS OF MODEL 2

\begin{tabular}{|c|c|c|c|}
\hline Variable & Full sample & State-owned & Private \\
\hline$\beta_{\mathbf{0}}$ & $0.099(29.32)^{* * *}$ & $0.080(19.20)^{* * *}$ & $0.126(21.26)^{* * *}$ \\
\hline$\beta_{1}$ & $0.408(31.07)^{* * *}$ & $0.457(27.69)^{* * *}$ & $0.353(15.94)^{* * *}$ \\
\hline$\beta_{2}$ & $-0.153(-2.49)^{* * *}$ & $-0.421(-4.43)^{* * *}$ & $0.017(0.20)$ \\
\hline$\beta_{3}$ & $-0.030(-2.79)^{* * *}$ & $-0.036(-2.42)^{* *}$ & $-0.031(-1.90)^{*}$ \\
\hline$\beta_{4}$ & $0.108(0.96)$ & $0.435(2.48)^{* *}$ & $0.033(0.21)$ \\
\hline $\mathbf{R}^{2}$ & 0.396 & 0.338 & 0.487 \\
\hline F-statistic & 326.26 & 246.40 & 94.72 \\
\hline Number & 5058 & 3360 & 1698 \\
\hline
\end{tabular}

\section{CONCLUSIONS OF THE STUDY}

Enterprises' labor cost stickiness is an important problem faced by enterprises' managers, and the labor cost stickiness reflects the ability of enterprises to adjust their labor costs, which is closely related to the long-term revenue of enterprises. By the study, it is found that China's listed companies have the labor cost stickiness. The degrees of labor cost stickiness have differences between the enterprises with different equities. The labor cost stickiness of state-owned enterprises is significantly stronger than that of private enterprises. At the same time, the higher the capital intensity is, the stronger the labor cost stickiness of enterprises is. The study of this paper extends the scope of cost stickiness research, and supports the existence of labor cost stickiness of listed companies in China. That the labor cost stickiness of capital-intensive enterprises is greater reflects the existence of shortage of technical talents in China, which is consistent with actual situations.

On the basis of the above research, the increase in labor costs has a great impact on the employment costs of enterprises, under the direction of the policy of reducing the burdens of enterprises put forward by our nation, on the premise of not affecting the security level, reducing the proportion of enterprises social security contributions will effectively reduce the labor cost of enterprises, and thereby reduce the laboradjustment cost of enterprises, so as to ease the labor cost stickiness. The capital-intensive state-owned enterprises have difficulties in the labor cost adjustment. On the one hand, it is because of lacking technical talents. On the other hand, it is because of the government's intervention. So the cultivation of talents should meet the requirements of modern enterprises' development, besides, in another new round of state-owned enterprise reforms, our nation will play a shareholder role; the original management style of "managing personnel, managing affairs and managing assets" will change, and the government will no longer interfere the operation affairs of enterprises, but mainly pay attention to the state-owned enterprises' added value, maintenance of value, becoming bigger and stronger, which will help state-owned enterprises' managers to adjust the efficiency of labor costs and ease the labor costs stickiness.

\section{REFERENCES}

[1] Andereon,M. C.,R. D. Banker, and N. J. Surya, 2003,”Are Selling General and Administrative C costs Sticky?" , Journal of Accounting Research ,41:47-63.

[2] Sun Zheng, Liu Hao. Study on the Cost "Stickiness" Behavior of Chinese Listed Companies [J]. Economic Research, 2004, (12): 26-34 + 84.(In Chinese)

[3] Banker, R. D. D. Byzalov, and J.M.Plehn-Dujowich. Sticky Cost Behavior: Theory and Evidence. Working Paper, 2011.

[4] Cai Fang. Demographic dividend and sustainable economic growth in China [J]. Gansu Social Sciences, 2013, (01): 1-4.(In Chinese)

[5] Liu Yuanyuan, Liu Bin. Labor protection, cost stickiness and business response [J]. Economic Research, 2014, (05): 63-76.(In Chinese)

[6] Zhang Min, Wang Chengfang, Liu Huilong. Redundant burden and the executive incentive of state-owned enterprises [J]. Finance Research, 2013, (05): 140-151.(In Chinese) 